Review

\title{
Staphylococcus aureus internalization in osteoblast cells: mechanisms, interactions and biochemical processes. What did we learn from experimental models?
}

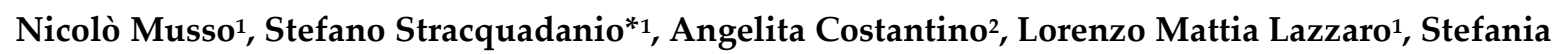

Stefani $^{1}$, Dafne Bongiorno ${ }^{1}$.

${ }^{1}$ Department of Biomedical and Biotechnological Sciences (BIOMETEC) - Medical Molecular Microbiology and Antibiotic Resistance laboratory (MMARLab), University of Catania, 95125 Catania, Italy; nmusso@unict.it (N.M.); s.stracquadanio@hotmail.it (S.Str); lazzclml@gmail.com (L.M.L.); stefanis@unict.it (S.S.); dbongio@unict.it (D.B.)

${ }^{2}$ Department of Drug Sciences, University of Catania, 95125 Catania, Italy; angelita25costantino@gmail.com (A.C.)

Correspondence: s.stracquadanio@hotmail.it; Tel.: +393-284-752-223

\begin{abstract}
Bacterial internalization is a strategy that non-intracellular microorganisms use to escape the host immune system and survive inside the human body. Among bacteria species, Staphylococcus aureus showed ability to interact and infect osteoblasts causing osteomyelitis as well as bone and joint infection, while also becoming increasingly resistant to antibiotic therapy and a reservoir of bacteria that can make the infection difficult to cure. Despite being a serious issue in orthopedic surgery, little
\end{abstract}


is known about the mechanisms that allow bacteria to enter and survive inside the osteoblasts, also due to the lack of consistent experimental models. In this review, we describe the current knowledge about $S$. aureus internalization mechanisms and various aspects of the interaction between bacteria and osteoblasts (e.g. best experimental conditions, bacteria-induced damages and immune system response), focusing on studies performed using the MG-63 osteoblastic cell line, so far the best model for the study of this phenomenon.

Keywords: Human Osteoblast; MG-63; Staphylococcus aureus, internalization mechanisms 


\section{Background}

During the first steps of growth, remodeling and recovery of the bone, different cell types co-exist and cooperate to form the extracellular bone matrix (EBM) (Lew and Waldvogel, 2004; Hudson et al., 1995). Among these, osteoblasts are the cells that form the bone and, together with osteoclasts, preserve its physiological homeostasis (Josse et al., 2015).

Pathological conditions, such as bacterial infections, are responsible for altered osteoblast activity. In detail, surgical procedures, especially in the presence of medical (orthopedic) devices, are responsible for an increased susceptibility of osteoblasts to osteomyelitis (Montanaro et al 2011; Kim et al, 2012; Hogan et al, 2013) and in this context Staphylococcus aureus represents a frequent intra- and extracellular pathogen (Heilmann, 2011).

The host-pathogen interaction between osteoblasts and S. aureus occurs through the recognition of pathogen-associated molecular patterns (PAMPs) by the pattern recognition receptors (PRRs) exposed on the extracellular surface of the osteoblasts. The consequent production of chemokines and cytokines will be responsible for the recruitment and subsequent activation of innate and adaptive immune cells, typical of the cellular inflammatory response (Claro et al., 2011). At the same time, the overstimulation of osteoblasts by $S$. aureus causes an increase in osteoclastogenesis with consequent osteoblast death, as well as an alteration of bone homeostasis (Figure 1) (Tucker et al., 2000; Wildaa et al., 2012).

The presence of proteins and glycans - such as type I collagen, bone sialoprotein, osteopontin, and fibronectin - make the EBM a perfect niche for S. aureus that binds these EBM components through multiple adhesins called MSCRAMMs, microbial surface components which recognize adhesive matrix molecules (Heilmann, 2011). Indeed, the S. aureus attachment to the EBM represents a key step in the onset of osteomyelitis, where type I collagen represents approximately $90-95 \%$ of the organic fraction of the EBM directly interacting with this pathogen (Figure 1).

Recently, it was demonstrated that the ability of S. aureus to internalize inside osteoblasts is a key strategy to protect itself and maintain the infection. On the contrary, osteoblast respond to S. aureus internalization by secreting inflammatory factors - such as cytokines, chemokines and growth factors 
- which, in turn, activate and recruit immune cells from the innate or adaptive immune systems (Figure 1) (Turner et al., 2014).

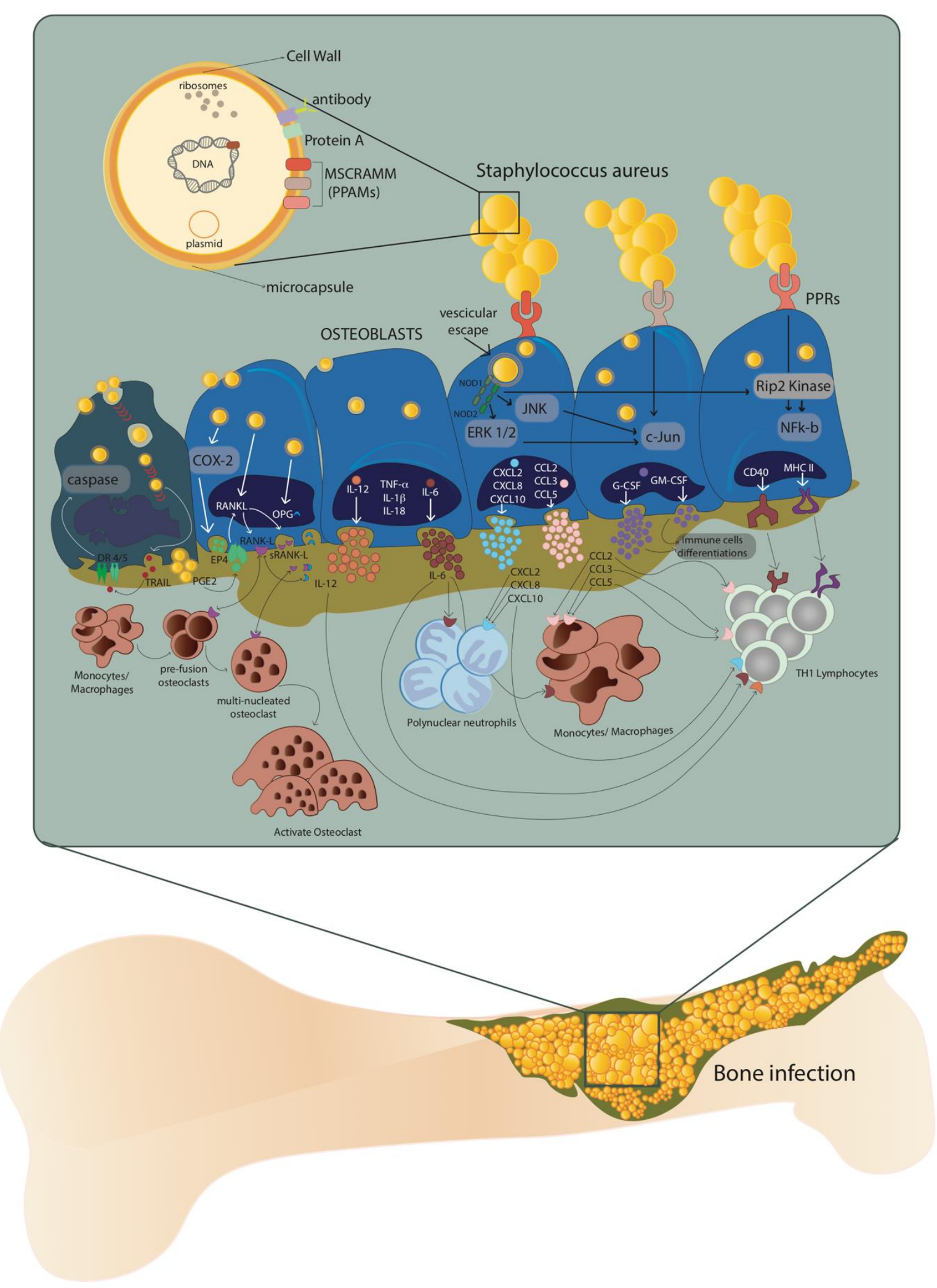

This illustration was designed by coauthor A. Costantino.

Figure 1: Host-pathogen interaction between osteoblasts and Staphylococcus aureus. After internalization, S. aureus escapes from vesicle and interacts with extracellular receptors TLR2 and TNFR-1, as well as intracellular 
receptors TLR 9 and NODs through $\alpha 5 \beta 1$ integrin and actin filaments of the osteoblasts. This interaction increases the expression of cytokines IL-1 $\beta$, IL-18, TNF- $\alpha$, the production and release of IL-6, IL-12 and the expression and release of chemokines CXCL2, CXCL8, CXCL10, CCL2, CCL3, CCL5 and growth factors G-CSF and GM-CSF. At the same time, the expression and production of CD40 and MHC II increase.

The excessive formation and activation of osteoclasts is caused by an increased RANK-L expression and production through the COX-2/PGE2 pathway. This leads to severe bone resorption as well as to decreased production of osteoprotegerin (OPG).

Finally, through the release of membrane-damaging virulence factors such as phenol soluble modulins (PSMs), S. aureus can cause necrosis of osteoblasts and their apoptosis by intrinsic and extrinsic caspase pathways. These processes can lead to the release of intracellular S. aureus, which can re-infect other osteoblasts.

Consequently, the ability of $S$. aureus to survive in osteoblasts after internalization also results in effective escape from the antibiotic therapy, which cannot penetrate inside the cells (Valour et al., 2015-a; Spellberg and Lipsky, 2012).

Therefore, a few years ago the hypothesis was confirmed that in addition to finding more effective antibacterial strategies, intensifying host defenses, as well as increasing understanding of the immune response may be advantageous for the development of new anti-infective strategies (Valour et al., 2015-b).

The use of in vitro culture models from different origins - including primary cells from different species, induced osteoblasts from pluripotent stem cells, as well as immortalized and malignant cell lines - has allowed a better understanding of osteoblast cell biology during infection processes (Czekanska et al, 2012).

To date, the progress of research in the field of orthopedic engineering, as well as the development of new therapies and biomaterials, increases the importance of these cell models. At the same time, a deeper knowledge of their phenotypic and genotypic status and their differences in relation to primary human osteoblast cells is needed, especially in order to choose the more appropriate experimental model.

MG-63 osteoblast-like cell line as an effective in vitro model to investigate host-pathogen mechanisms during S. aureus infection

Although preclinical models are known to offer an essential prescreening method for testing new biomaterials useful in the treatment of orthopedic disorders, the increasingly restrictive regulations 
for the use of in vivo models and the ever-increasing demand for primary cells from healthy or sick donors have led to the development of "continuous" osteoblast cell models. Among these, humanand animal-derived primary cells (Abe et al., 2000; Bellows et al., 1986; Cao et al., 2006; EcarotCharrier et al 1983; Collignon et al., 1997), immortalized cell lines (Wang et al., 1999; Harris et al., 1995), malignant cells (Billiau et al., 1977; Rodan et al., 1987; Potent and Saksela, 1967) and induced pluripotent stem cells (iPSs) are used not only in drug and biomaterials testing, but also in bone biology investigations.

Certainly, primary cells, deriving directly from patients, better reproduce the behavior of the original cellular niche, resulting in a preclinical model closer to clinical conditions. Over the years, however, researchers and physicians have been realized that the phenotypic and often genotypic differences of these cells isolated from different patients make it difficult to study the disease under examination and consequently to establish the best therapeutic strategy.

An improvement in the knowledge of bone biology and, in particular, osteoblast cells has been achieved through the development of stabilized osteoblast cell lines as models for the in vitro investigation of cell differentiation regulation, cytokines and hormone regulation, matrix protein synthesis and secretion and molecular mechanisms of bone diseases. At the same time, these models were found to be useful for the evaluation of the cytocompatibility and osteogenicity of new biomaterials (Czekanska et al, 2012).

There is no evidence indicating the superiority of one model over the others; therefore, an evaluation of their respective advantages and disadvantages, on the basis of studies to be conducted, is important.

Primary cultures represent an in vitro model that uses cells directly obtained from tissue biopsies $\left(\sim 1 \mathrm{~cm}^{3}\right)$ or organ dissections. These cells have the unique characteristic of maintaining their genetic, morphological and functional features. This makes them the best representative indicators of normal cell phenotype and early-stage disease progression, and as such they are commonly used as in vitro tools for pre-clinical and investigative biological research and toxicological studies, besides reducing the number of animals required for preclinical toxicology studies at an initial stage, making them cost-saving. 
Even though primary human osteoblasts tend to preserve their differentiated phenotype in vitro, after a certain number of cell divisions these cells have a limited lifespan and will stop dividing (or senesce) and may be more difficult to grow and maintain than a continuous (immortalized) cell line. Induced variability in primary cells obtained from donors and in subculture practices is one of the main challenges faced by researchers studying cell signaling pathways (Czekanska et al, 2012).

Specifically, it has been shown that the age of the donor influences the proliferative capacity of isolated cells, whose proliferation times are doubled if derived from patients over the age of 65 (Voegele et al., 2000; Jonsson et al., 1999).

Furthermore, bone ageing, defined as a change in the degree and distribution of bone mineralization, is also age-dependent. This is reflected in the physiology of isolated osteoblast cells, characterized not only by slower proliferation, but also by phenotypic modification (Bonjour et al., 1991; Bergot et al., 2009). Likewise, the expression of genes and the synthesis of proteins associated with the osteoblast phenotype are also influenced by the age of the donor, as well as by the anatomical site of isolation. For example, it is now known that the FGF $\beta$ and IGFII gene expression is downregulated in osteoblast cells isolated from the mandible, as well as the synthesis of type I collagen and osteonectin shows higher expression in cells isolated from fetal to 20 years bone donors, while a $65 \%$ decrease of collagen levels was observed in cells from donors older than 20 years (Fedarko et al., 1992).

Moreover, when these cells are extracted ex vivo and transferred to culture environment, they may lose their structural and functional characteristics. In this regard, cells having completely different morphology in vivo at the tissue level may show similar morphology in the culture environment (Kasperk et al., 1995; Martinez at al., 1999).

Thus, donor age, site of isolation and the gender differences that we have discussed so far are just some of the factors that can influence the behavior of primary human osteoblast cells and, in turn, confer different times of phenotypic modification in vitro. As a result, in the absence of a homogenous target of patients/donors, obtaining cultures of osteoblasts suitable for the study of basic applied biology or particular mechanisms, such as infection, is not efficient.

The ease of obtaining results in experiments and their repeatability, as well as the ease of maintenance, the unlimited number of cells without the need for isolation and the relative phenotypic 
stability of immortalized or continuous MG-63 cell lines has allowed, in some respects, to overcome the limits imposed by cells primarily derived from the bone (HObs). Although these cell models differ in some respects from primary osteoblast cells, Czekanska et. al showed that MG-63 cells show some distinct similarities to HObs (Czekanska et al., 2014).

According to Billiau et al., the MG-63 cell line is derived from a juxtacortical osteosarcoma diagnosed in the distal diaphysis of the left femur of a 14-year-old male (Biliau et al., 1977). When cultured, these cells appear as rapidly proliferating aggregates without exhibiting contact inhibition (Heremans et al., 1978).

The similarity between MG-63 and $\mathrm{HOb}$ was already studied several years ago, when Franceschi et al. observed the response of these cells to 1,25-dihydroxyvitamin D3 (1,25 (OH) 2D3) as an effect on cell morphology and on the phenotype comparable to normal osteoblasts (Franceschi et al., 1988).

More recent studies have shown that the cell growth kinetics of MG-63 was comparable to that of $\mathrm{HOb}$ as the exponential growth phase was observed from day 2 to day 6 , followed by a plateau phase from day 6 to day 10 (Czekanska et al., 2014). This result is confirmed by the ability of infinite proliferation typical of malignant cells, such as MG-63 cells, where the lack of intrinsic cell cycle control contributes to tumor progression.

Czekanska et. al also observed that the activity of alkaline phosphatase, an enzyme identifying mature osteoblasts, was lower in MG-63 cells than in primary cells (Czekanska et al., 2014). This result confirmed the different degree of differentiation of MG-63 towards a more immature phenotype, compared to $\mathrm{HOb}$.

The expression analysis of key osteoblast-specific genes (Czekanska et al., 2014) showed that the transcription factor Runx2 - which regulates gene expression of all-important bone matrix proteins (including ALP, OC, BSP and type I collagen) - is more expressed in MG-63 than in HOb, except on day 2 (Schinke et al., 2002; Ducy et al., 1997).

As previously introduced, type I collagen is essential for the function of osteoblast cells (Wenstrup et al., 1996) and is overexpressed in the phase preceding matrix mineralization (Ryoo et al., 1997; Kirkham et al., 2007), in order to allow the formation of fibrils and a subsequent physiological maturation of the matrix. On the contrary, MG-63 cells show low expression of type I collagen as well as of osteocalcin (Czekanska et al., 2014). 
Consequently, the reported studies highlight the limitations of these cells as a model for the phenotypic development of osteoblasts as well as for the evaluation of the mineralization of the matrix and the properties of new biomaterials (Czekanska et al., 2014).

On the other hand, the MG-63 cell line proved to be a valid in vitro model for the study of bacterial infection mechanisms, especially during S. aureus internalization (Ahmed et al., 2001; Nair et al., 2001; Khalil et al., 2007; Testoni et al., 2011; Jauregui et al., 2013; Valour et al, 2015-a).

In 2010, Schroder and Tschopp demonstrated that the innate immune response against pathogens involves activation of an inflammatory pathway known as the inflammasome activation pathway (Schroder \& Tschopp, 2010). Inflammasomes are multiprotein signaling complexes that are assembled following recognition of stress/pathogenic signals; among these, caspase-1 is the most involved (Lamkanfi \& Dixit 2009). Upon stimulation by pathogens, caspase-1 binds to an adapter molecule known as ASC (apoptosis- associated speck-like protein) (Mariathasan et al., 2004). This binding leads to the autocatalytic cleavage of caspase- 1 , the processing of pro-IL- $1 \beta$ and pro-IL-18 and the secretion of mature IL-1 $\beta$ and IL-18, triggering in some cases even to an inflammatory form of cell death (pyroptosis) (Strowing et al., 2012). Recent studies have shown that this also applies to S. aureus and MG-63 cells (Leite et al., 2020; Dinarello et al., 2012).

Finally, in a previously published work, we demonstrated that internalization is a pathophysiological pathway of some methicillin-resistant S. aureus (MRSA) which depends on the total number of cells infected and not on the number of bacterial cells that enter each osteoblast. Furthermore, even if our strains were not homogeneous in terms of genetic backgrounds and virulence factors, ST22-IVh and ST239-III S. aureus showed higher intracellular persistence in host cells, making them more prone to developing chronic and recurrent infections (Bongiorno, Musso et al., 2020).

\section{MOI and invasiveness of different bacterial strains}

In the presence of prosthetic devices, complete eradication of bacterial infection is often a challenging task. Internalization in non-professional phagocytes is an important pathogenic mechanism actuated by bacteria to elude host defenses and medical therapies. The efficiency of invasion differs across 
bacterial species and adjustments to the titer of the microbial inocula used in the assay are often needed to enumerate intracellular bacteria.

There is a precise relation between the inoculum, in terms of multiplicity of infection (MOI), and the internalized bacteria. Furthermore, there is a relationship between MOI, internalized bacteria ratio and medical therapies (Bhavsar et al., 2007; Ellington et al., 2006).

Intracellular invasion occurs through a variety of pathogenic species. Some bacteria are pathogenic obligate intracellular, while other only become intracellular to escape the host immune system. Among these, the following genera are the most representative: Mycobacterium; Escherichia; Salmonella; Listeria; Shigella; Legionella; Chlamydia; Yersinia; Streptococcus; Staphylococcus and Enterococcus (in particular E. faecalis). S. aureus is the only one capable of causing the onset of clinically relevant pathogenic mechanisms and consistently invade osteoblast cells (Maali et al., 2016).

Different MOIs have been adopted depending on the bacterial species tested. For example, a MOI of 100:1 (bacteria: host-cells) is the inoculum titer most frequently used to test S. aureus. The inoculum size increases to 500:1 for S. epidermidis (Valour et al., 2013; Khalil et al., 2007) and 1000:1 for S. lugdunensis (Campocia et al., 2016). The different MOIs used showed rapid and efficient internalization of $S$. aureus at low inoculum sizes and inefficient internalization of other species at high inoculum sizes.

Two other parameters are used to express the potential of invasiveness of bacterial strains: i) the Number of Internalized Bacteria (NIB) at an established MOI, expressed in term of CFUs per number of eukaryotic cells, influenced by the MOI used; and ii) the Percent of Internalized Bacteria (PIB), which represents the percent fraction of the inoculum taken up by eukaryotic cells; this value is not affected by the MOI and can be used to express the degree of invasiveness of prokaryotic cells into eukaryotic cells.

Examining the correlation between MOI values and PIB values, it emerged that - over a broad range of inoculum sizes - the MOI did not appear to affect PIB values (Campocia et al., 2018). PIB values can be used to compare strain invasiveness without fearing major effects resulting from varying MOIs.

However, a new parameter was proposed to express the invasiveness of bacterial strains: the Internalization Minimal Inoculum (IMI), corresponding to the lowest MOI required for the 
internalization of a single bacterium. This value is inversely related to invasiveness and corresponds to the lowest concentration at which internalization occurs under the test condition used. Internalization at a 1:1 MOI inoculum (11M) corresponds to the number of bacteria internalized when hypothetically exposing each eukaryotic cell to a single bacterium (i.e. using a 1:1 MOI). Its value is proportional to the degree of invasiveness of the strain given by the $\log 10$ of the IMI value (LIMI), obtained from the regression curve of Log MOI vs Log (CFU).

In conclusion, the most used parameters to express the intracellular invasiveness of bacterial strains are the NIB and PIB values. PIB values can be used across a broad range of MOIs without fearing the influence of the inoculum size. Ultimately, PIB values do not depend on the MOI, whereas NIB values are strongly MOI-dependent.

Therefore, we can speculate that the internalization process can be influenced by several factors, such as: i) bacterial sedimentation rate, influenced by the microbe size, shape and tendency to agglomerate and by the viscosity of the medium; ii) composition of the culture medium; iii) cell line used in the assay, considering its histological origin, phagocytic activity (professional or non-professional phagocytic cells in primary or secondary cultures), level of expression of integrins capable of interacting with adhesins; iv) bacterial strain type (bacterial species and genes encoding for invasiveness).

As already mentioned, different MOIs have been used in several studies depending on the strains tested. These include e.g. S. aureus, S. epidermidis, and S. Iugdunensis, opportunistic pathogens causing implant-related infections.

These species can survive antibiotic therapies through different mechanisms related to genetic determinants, biofilm production and penetration into eukaryotic cells as the main causes of chronic infections. Furthermore, eukaryotic cells are impermeable to many antibiotics, such as rifampin, that are able to pass through the prokaryotic cell membrane (Stewart et al.,2001; Arciola et al.,2012).

Many staphylococcal species, other than S. aureus, are emerging as opportunistic pathogens capable of causing serious and persistent implant-associated infections. S. epidermidis is the second most isolated staphylococcal species responsible for orthopedic infections and able to internalize into 
osteoblasts (Khalil et al, 2007; Valour et al. 2013). S. Iugdunensis is an emergent pathogen responsible of periprosthetic infections (Arciola et al.,2007).

The invasive potential of different bacterial species and their ability to internalize into the MG-63 cell line was evaluated using a method based on microtiter plates, where they were challenged with osteoblasts.

Campocia et al. in 2016 have used different MOIs for each Staphylococcus species tested. The MOI value was always recorded in order to know the inoculum sizes actually reached: MOI 560:1 for $S$. epidermidis; and MOI 1844:1 for S. lugdunensis.

S. epidermidis has an extremely low rate of internalization, not comparable with that observed for $S$. aureus. Furthermore, the bacterial survival rate appeared rather marginal. Most S. epidermidis tested with MOI 500:1 showed a relatively low internalization ( $<50 \mathrm{CFU})$, while other strains showed high internalization $(>50 \mathrm{CFU})$.

Some groups of bacteria appear homogeneous in terms of CFUs internalized regardless of the inoculum size, while others exhibit some heterogeneity in spite of similar inoculum levels. S. lugdunensis showed very low levels of internalization regardless of the size of inoculum, even though it was tested with a relatively high MOI (1000:1).

The species considered exhibited marginal rates of internalization compared to $S$. aureus, since $S$. aureus showed higher rate of internalization at a lower MOI (100:1).

S. aureus requires a very low inoculum to reach a high internalization rate, whereas S. epidermidis cell invasiveness remains low and marginal. This finding suggests that the active mechanisms of invasion exhibited by S. aureus are either absent or much less efficient in S. epidermidis. Similarly, the clinical isolates of S. lugdunensis showed low level of internalization (Figure 2) (Campocia et al., 2016). 


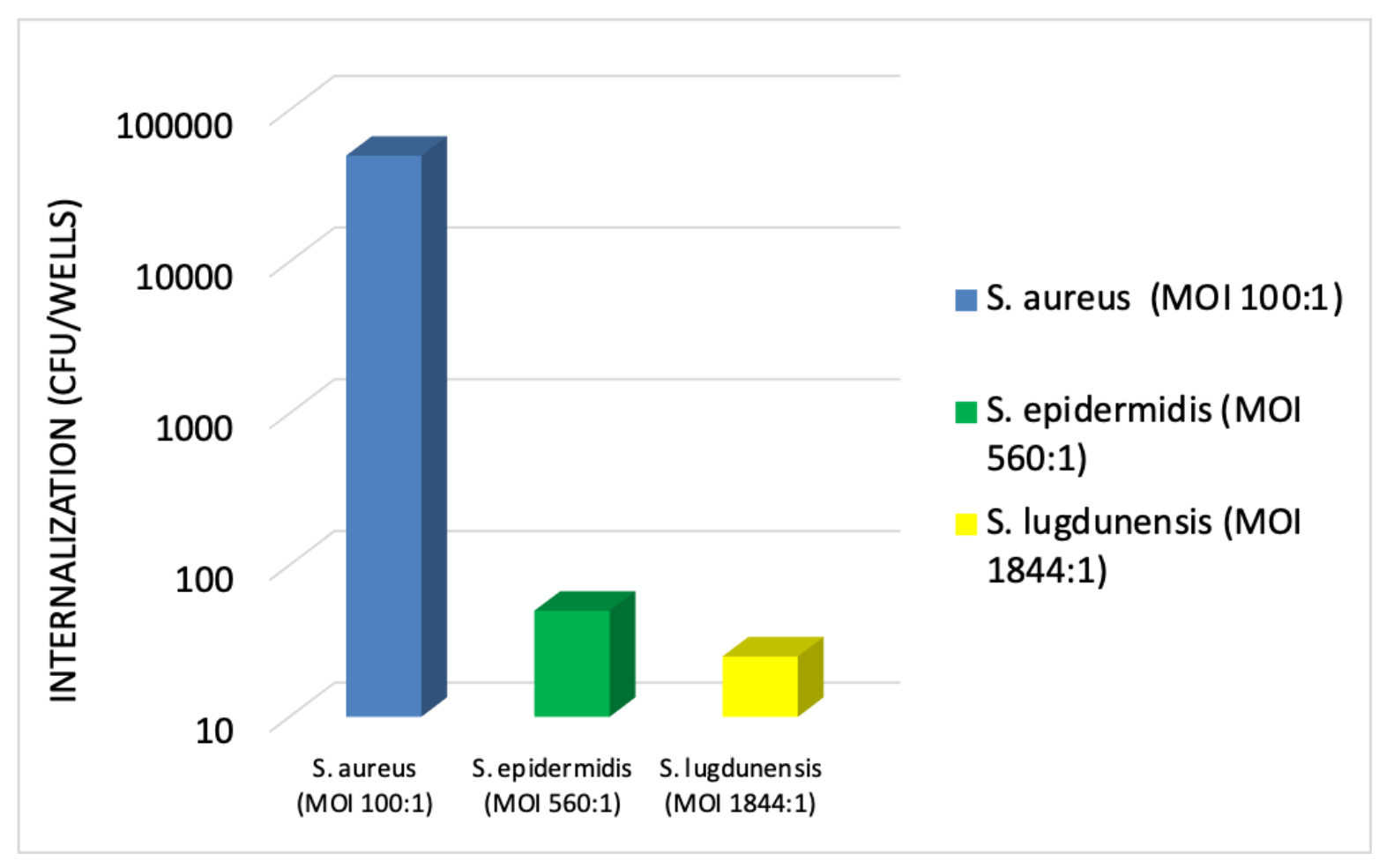

Figure 2. Bar-graph illustrating the internalization of S. aureus, S. epidermidis and S. lugdunensis at different MOIs on a logarithmic scale (Modified from Campocia et al., 2016).

To confirm the use of diverse MOIs in the internalization process, studies performed by Valour et al. (2013) compared the different behavior of S. aureus and S. epidermidis during internalization. As previously shown, S. epidermidis has a low rate of internalization, being an innocuous commensal of the human skin and mucous membranes, but it is considered a leading opportunistic pathogen (Valour et al., 2013).

The contrast between the low incidence of S. epidermidis orthopedic device infection and the highly prevalent $S$. epidermidis carriage suggests that $S$. epidermidis bone and join infections may either correspond to accidental events due to colonizing strains or to a specific, more virulent subpopulation of commensal isolates.

Two predominant mechanisms have been proposed to be implicated in orthopedic device infections, i.e.: bacterial invasion and persistence in non-professional phagocytes, such as osteoblasts (Ellington et al.,1999); and the bacteria ability to form biofilm (Costerton et al., 1999; Brady et al, 2008). 
To verify the ability of internalization of S. epidermidis into the MG-63 cell line, an invasion assay of S. epidermidis was carried out using a MOI of 500:1 for S. epidermidis and a MOI of 100:1 for S. aureus (used as control strain).

The results of this assay demonstrated that the number of internalized bacteria was MOI-dependent. There was a difference in bone cell invasion rates between $S$. epidermidis and $S$. aureus strains. $S$. epidermidis showed a lower rate of internalization. This can be due to several factors, such as the "cell line effect" - i.e. the use of the MG-63 cell line - and the acquisition of some phenotypic characteristics that may not reflect the in vivo reality (Pautke et al., 2004).

To exclude a bias due to a "cell line effect", the low internalization rate of S. epidermidis was confirmed using primary bone cells. For this reason, all assays were repeated using primary human osteoblasts (Valour et al., 2013).

Fibronectin-binding protein-like molecules are absent in S. epidermidis, therefore the process of invasion is different from that of $S$. aureus.

Finally, the internalization of S. epidermidis in human osteoblasts is not a common pathophysiological mechanism in orthopedic device infections, contrary to what was observed in other clinical situations or with other strains (e.g. S. aureus).

MOI values were selected depending on the strain used and several other factors.

In general, the best choice is to use as few bacteria as possible to reduce cell damage, as important strain-dependent differences may be missed if extended incubation periods or large inocula are used (Edwards et al., 2011).

Hamza et al. (2014) performed an infection experiment using rat osteoblasts and S. aureus at different MOIs over different incubation times. They found that intracellular CFUs increased from MOI 100 to MOI 500 and that MOIs greater than 500 did not result in an increase in intracellular CFUs. Osteoblast viability did not change significantly in a MOI range of 100-1000. As a result, high intracellular CFUs and high osteoblast viability were reached at MOI 500 (Hamza et al., 2014). 
In the study carried out by Bongiorno et al. (2020), the frequency of internalization was evaluated in a cell culture model of infection using S. aureus and MG-63 osteoblasts at a MOI of 100:1. In order to assess this MOI, they first tested MG-63 infection with S. aureus ATCC 12598 at the following MOIs: 12:1, 50:1, 100:1, and 200:1. It was observed that, at MOI 12 and 50, the ability of S. aureus to internalize into nonspecialized cells, such as the osteoblasts, was very limited, while with a MOI of 200 MG-63 cultured cells showed phenomena of cytotoxicity (Bongiorno, Musso et al., 2020).

\section{Interaction between S. aureus and MG-63 osteoblast cells}

S. aureus is capable of inducing DNA damage in several host-cell, such as osteoblast-like MG-63 cells. The pathogens develop multiple strategies to promote infections (Chumduri et al 2016), interfering with survival pathways (Alto et al 2012) and suppressing the immune response of the host, thus facilitating the establishment of chronic infections and promoting host cell transformations (Johnson et al, 2017).

\section{DNA damage}

Bacteria can damage the host DNA directly and indirectly - e.g. through the production of reactive oxygen species (ROSs). S. aureus induces disease especially during chronic infections and the chronicization of $S$. aureus infection leads to a phenotypical adaption from a highly virulent to a less virulent form called "small colony variant" (SCV), characterized by increased intracellular persistence, diminished ability of immune system stimulation and lower ability to induce low level of cytokines release (Trouillet-Assant et al., 2016).

S. aureus versatility during infection is due to the production of many factors, the most notable being: i) pore forming toxins; ii) exfoliative toxins, involved in tissue disintegration; iii) adhesins, involved in tissue colonization; iv) ROSs, that can lead to the formation of deleterious oxidative host DNA lesions (promoting the oxidation of guanidine forming 7,8-dihydro-8-oxoguanine or 8-oxoG); v) cyclomodulins, which alter the host cell cycle to promote infections.

Deplance et al. (2019), demonstrated that S. aureus induces ROS-mediated associated DNA damages, followed by DNA repair, and identified "phenol soluble modulin" (PSM alpha) and lipoproteins 
(Lpls) as the effectors of this phenomenon. Consequently, 8-oxoG, is more expressed in the infectedcells.

$\mathrm{H} 2 \mathrm{AX}$ is a protein used as a marker of DNA damage. In particular, Deplace et al. demonstrated that S. aureus induces dose-dependent $\mathrm{H} 2 \mathrm{AX}$ phosphorylation $(\gamma \mathrm{H} 2 \mathrm{AX})$ in osteoblast-like MG-63 cells, in the presence of double-strand break (DSB) damage without apoptosis.

In response to the bacterial agent activity, host-cells promote the formation of highly cytotoxic ROSs as a defense mechanism against bacteria.

The role of ROSs in causing DNA damages was investigated by incubating host cells with N-acetylcysteine (NAC), a ROS-inhibitor. The incubation of host cells with NAC $1 \mathrm{~h}$ for $6 \mathrm{~h}$ and $20 \mathrm{~h}$ before infection with $S$. aureus prevented induction of DNA damage, showing that ROSs are involved in $S$. aureus-induced DNA damage (Deplance et al., 2019).

8-oxoG DNA lesion is the most common type of lesions that can generate DNA double strand breaks when occurring during DNA replication and is thus deleterious (van Loon et al., 2010). Eukaryotic cell DNA damage may reversibly arrest cell cycle progression to allow DNA repair (Reinhardt et al. 2009; Smith and Bayles, 2006). In addition to DNA damage, cell cycle arrest may be associated with the actin state organization (Heng et al. 2010, Rupes et al 2001).

S. aureus triggers ROS-mediated DNA damage, thus affecting the genomic integrity and/or regulating a gene transcriptional activation. The induced DNA damage depends on the balance between the levels of the expression of PSM $\alpha$ and Lpls and on bacterial adaptation during chronicization, linked to the maintenance of the host genome integrity.

Furthermore, previous studies have proven that the S. aureus virulence factors PSMs and Lpls had properties similar to cyclomodulins since they induce G2/M transition delay in infected cells (Deplanche et al., 2015; Nguyen et al., 2016). The consequences of S. aureus-induced G2/M delay were investigated: the G2 cellular phase is advantageous for bacterial intracellular replication and is associated with a decreased production of antibacterial peptides that may contribute to the persistence of the infection (Deplanche et al., 2015; Alekseeva et al., 2013). 
As already known, persistent infections are associated with a wide plethora of virulence factors regulated by the "accessory gene regulator" (agr system).

Valour et al. (2015-b) showed that MSSA internalization rates inside osteoblasts were significantly higher in chronic bone and joint infection (BJI) isolates than in acute BJI isolates, and that no difference existed between the two groups in terms of cytotoxicity. Similarly, no differences in the ability of both groups to convert to the SCV phenotype was observed, and biofilm formation was not different between acute and chronic BJI isolates either.

Delta-toxin negative strains tend to be more represented in chronic BJI and the absence of delta-toxin expression was associated with higher internalization rates. In the same study, the lack of a relationship between BJI chronicity and bacterial genetic backgrounds or virulence factors as well as an association between osteoblasts invasion and agr deficiency were reported. Moreover, acute infections are usually associated with a functional agr system. agr dysfunction appears to occur during infection and in the presence of persistent bacteremia. Furthermore, infection chronicity appeared to be the main factor associated with agr dysfunction. A strong relation between agr dysfunction and the bacterial phenotypic mechanism associated with BJI chronicity - including enhanced biofilm formation and increased osteoblastic invasion with reduced infection-induced cytotoxicity - was revealed. The loss of agr function that occurs during certain infections seems to be linked with BJI chronicity through the promotion of an intraosteoblastic $S$. aureus reservoir caused by a limitation of intracellular staphylococcal cell damage and through enhanced biofilm formation (Valour et al, 2015-b).

Finally, the agr-system controls the expression of PSM encoding genes (PSM $\alpha 1$ to 4 , PSM $\beta 1$ and 2 and $\delta$-toxin, sometimes referred to as PSM $\gamma$ ) (Otto, 2010; Queck et al., 2008). PSM stimulates the production of inflammatory cytokines (Syed et al., 2015) and has a role in IL-1 $\beta$ production by infected MG-63 cells. This was demonstrated by analyzing a WT-strain of S. aureus and a S. aureus LAC $\Delta \mathrm{psm} \alpha \beta$ hld mutant for their ability to stimulate the release of IL-1 $\beta$. The level of IL-1 $\beta$ was lower in the supernatant of WT MG-63 cells exposed to LAC $\Delta$ psm $\alpha \beta$ hld mutant compared to the level observed in the supernatant of WT MG-63 cells exposed to wild-type LAC (Figure 3). 


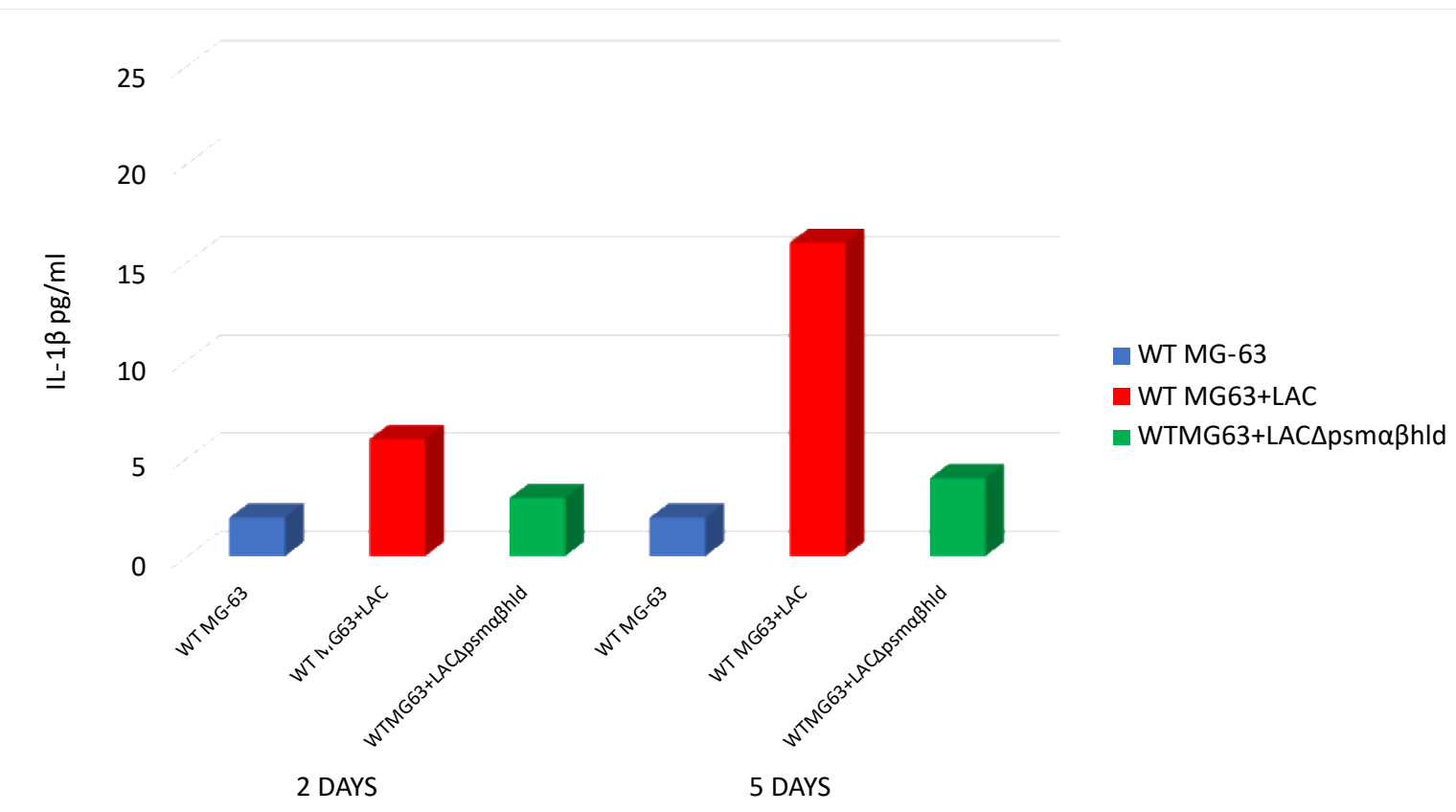

Figure 3: S. aureus PSM stimulates IL-1 $\beta$ release from infected osteoblast-like MG63 cells. 2- and 5-days postinfections, the level of IL-1 $\beta$ was determined by ELISA assay under different conditions (modified from Leite et al., 2020)

Immune system

After pathogen invasion, the immune system (IS) recruits an inflammasome, an immune signaling platform that activates proteases such as caspase-1, that proteolytically matures and promotes the secretion of mature IL-1 $\beta$ and IL-18.

The innate immune response against microbes involves an inflammatory pathway known as the activation of inflammasomes. Caspase- 1 is synthesized in cells as a $45 \mathrm{kDa}$ inactive precursor that will be cleaved to reach its mature form consisting of two subunits of 20 and $10 \mathrm{kDa}$ after inflammasome activation (Lamkanfi \& Dixit, 2014). After stimulation by pathogens, inflammasome assembly leads to the autocatalytic cleavage of caspase-1, the processing of pro-IL-1 $\beta$ and pro-IL-18 and the secretion of mature IL-1 $\beta$ and IL-18.

It was reported that the expression of inflammasome-associated proteins was significantly higher in infected bones than in uninfected ones, as found in patients with osteomyelitis. In a S. aureus-induced murine osteomyelitis model, a higher expression of these proteins was reported (Zhu et al., 2019). 
Leite et al. 2020 used the MG-63 cell line as a model of infection with S. aureus strain and a CASP1-/mutant MG-63 cell line (obtained by using the CRISPR-Cas9 editing system) to evaluate the role of caspase- 1 after the invasion process. To test caspase- 1 activation, MG-63 cells were incubated with LPS and ATP, two inflammasome activators. Western-blot analysis showed that incubating MG-63 cells with the activators resulted in the activation of caspase-1, while the ELISA test revealed a production of low levels of IL-1 $\beta$ after $2 \mathrm{~h}$ and a higher production after $6 \mathrm{~h}$ (Figure 4).
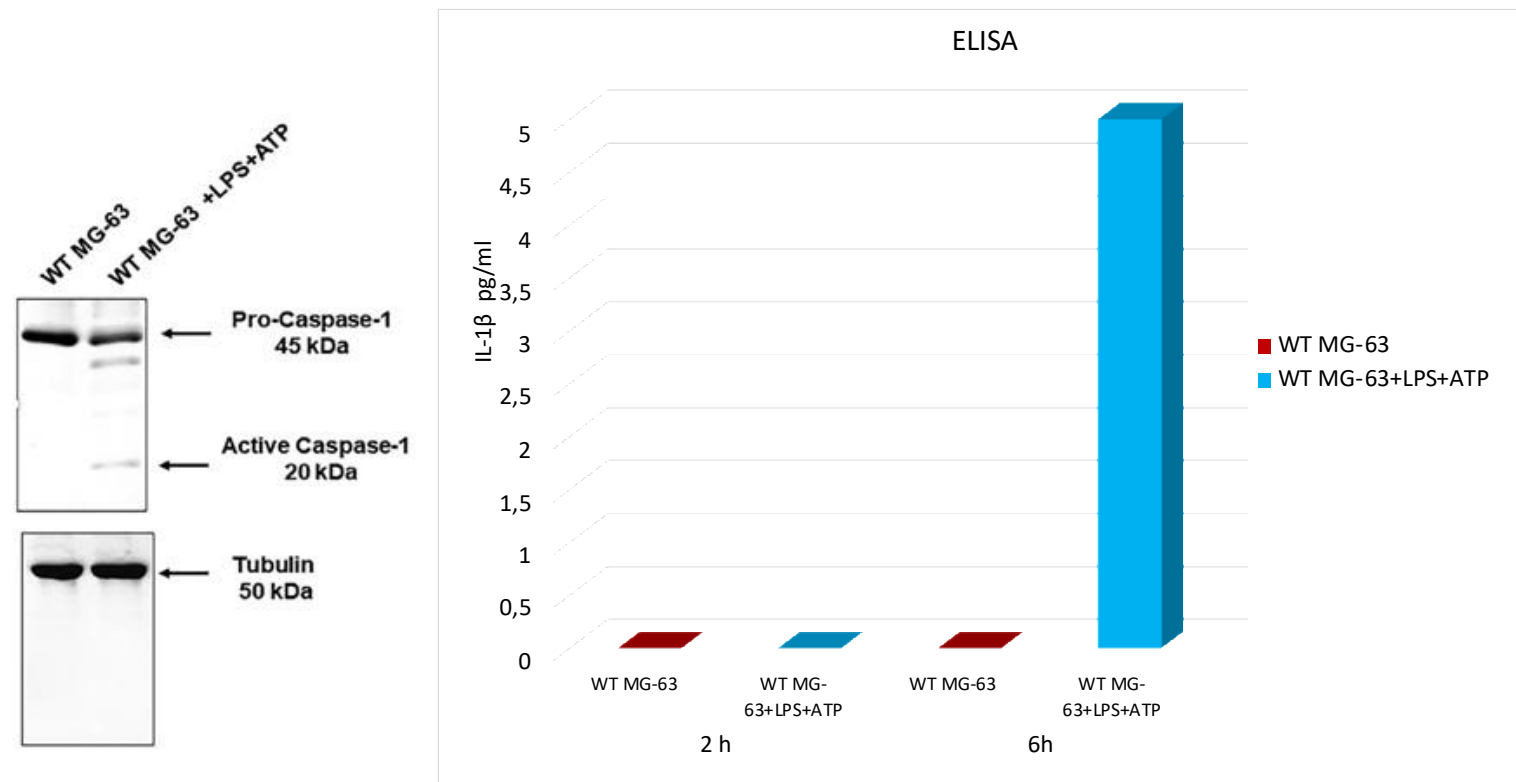

Figure 4: Caspase activation in the MG-63 cell line. Western blot analysis confirmed that the WT MG63 cells incubated with LPS+ATP produce active caspase-1. An ELISA assay was performed to confirm IL-1 $\beta$ production in the WT MG63 cell line and in WT MG-63+LPS+ATP at 2h and 6h (from and modified from Leite et al., 2020).

Inflammasome recruited and activated pro-caspase-1, which promoted IL-1 $\beta$ and IL-18 maturation. Six hours after the beginning of the infection with a 50:1 MOI, the number of $S$. aureus CFUs recovered from mutant cells was significantly higher than those recovered from WT MG-63 cells. WT MG-63 cells and CASP1-/- mutant MG-63 clones expressed apoptosis associated speck-like protein, while only WT MG-63 produced IL-1 $\beta$ after exposure to inflammasome (Lieite et al., 2020).

To evaluate the role of $S$. aureus as an inflammasome activator, IL-1 $\beta$ production in WT and CASP1-/mutant MG-63 cells was measured. In the latter case, a lack of IL-1 $\beta$ was recorded (in contrast to what observed in WT MG-63 cells). During these experiments, several S. aureus strains were used. All strains induced IL-1 $\beta$ release, showing that this mechanism is strain-independent. Moreover, IL-1 $\beta$ 
was not detected in the supernatant of MG-63 cells exposed to killed bacteria, suggesting that factors associated with viable bacteria are involved in inflammasome activation.

S. aureus clearance by osteoblast-like MG-63 cells depends on caspase- 1 . Indeed, the number of viable bacteria recovered from infected cells was significantly higher in CASP1-/- mutant MG-63 than in WT MG-63. These evidences suggest that the lack of caspase-1 impairs the ability of osteoblast-like cells to limit S. aureus growth. A drastic increase in the proliferation of internalized bacteria in osteoblastic mutant cells had already been highlighted (Leite et al., 2020) (Figure 5).

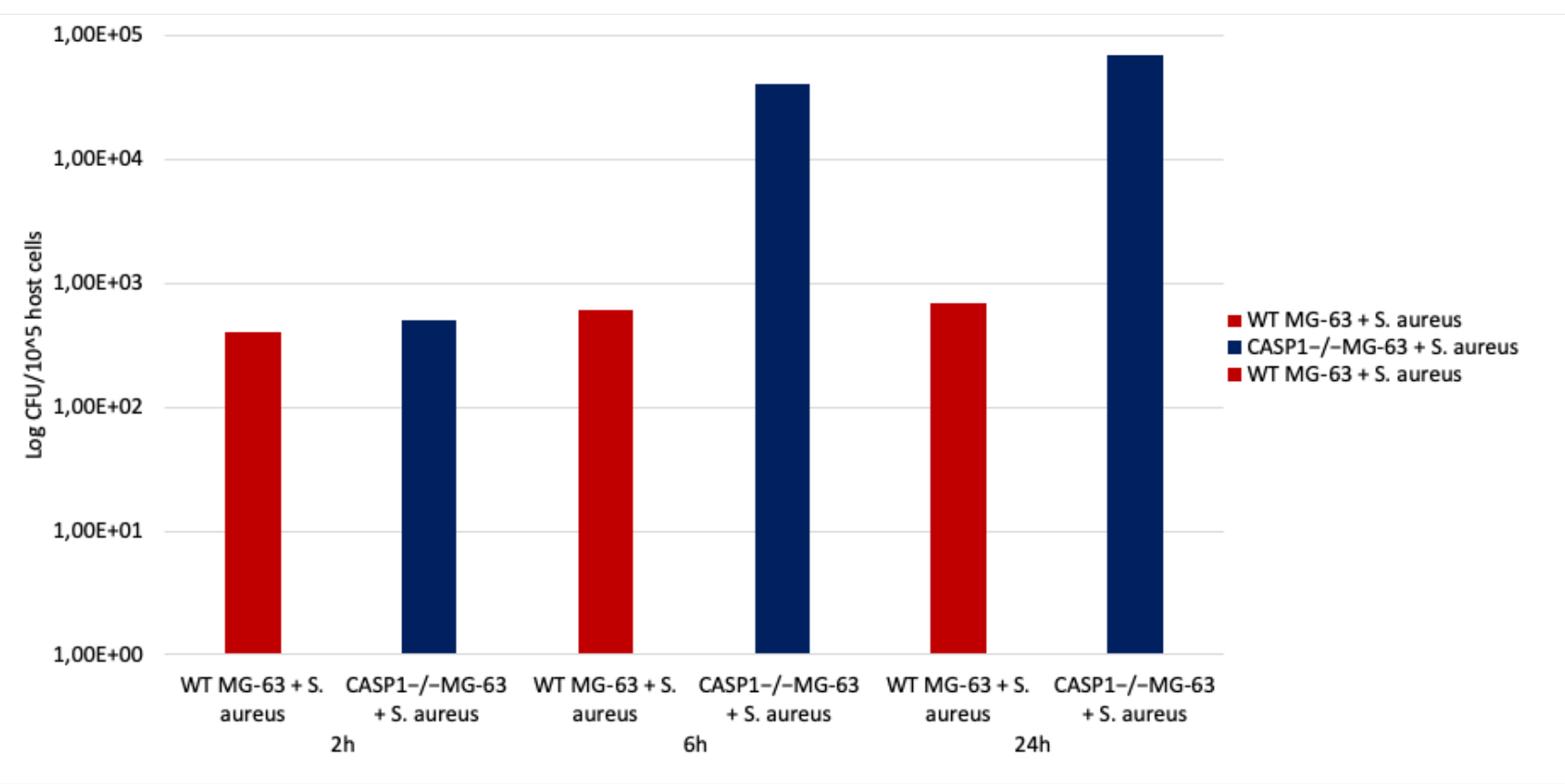

Figure 5: Involvement of caspase-1 in bacterial clearance in WT MG-63 and in CASP1-/- mutant MG-63 at different time points (Modified from Liete et al., 2020).

In fact, a correlation exists between the lack of caspase-1 activation and a failure in limiting S. aureus replication inside phagocytic cells (Cohen et al., 2018; Sokolovska et al., 2013). Furthermore, it was demonstrated by Dinarello, et al. (2012) that human osteoblasts-like MG-63 cells induce an immune response against $S$. aureus through inflammasome activation and processing of IL-1 $\beta$, the main inflammatory cytokine. Finally, CASP1-/- mutant MG-63 cells inability to limit intracellular replication of $S$. aureus was reported. This work points out that active caspase-1 prevents exacerbated intracellular replication of $S$. aureus. Osteoblasts therefore are not passive bystanders, but active players in host defenses against S. aureus infection (Dinarello et al., 2012). 
As mentioned above, S. aureus is capable of inducing the production of cytokines and chemokines by binding to extracellular or intracellular receptors. In this way, S. aureus induces inflammatory cell recruitment leading to bone loss (Josse et al, 2015). Cultured osteoblasts infected with bacteria secrete immune modulators of the inflammatory response, cytokines and chemokines, which trigger bone inflammation and destruction (Miyamoto et al.,2009; Bost et al., 2001).

To counteract internalization in osteoblasts and the resulting inflammatory process, serratiapeptidase (SPEP) - a metalloprotease produced by Serratia marcescens already used as an antiinflammatory agent - was used (Bhagat et al., 2013). This molecule modulates adhesin expression, enhances antibiotic efficacy toward biofilm-forming bacteria and interferes with S. aureus adhesion to abiotic surfaces (Papa et al 2013; Selan et al. 2015).

Selan et al. (2017) showed the effect of SPEP during internalization process of S. aureus in the MG-63 cell-line, using a MOI of 30:1.

The internalization efficiencies of SPEP-pretreated bacteria and SPEP-untreated bacteria were compared. SPEP-pretreated S. aureus exhibited significantly reduced efficiency of internalization. MG-63 cells incubated in absence of bacteria and with/without SPEP treatment showed that MG-63 proliferation remains unaffected, while when bacteria were pretreated with SPEP, a slight, statistically non-significant decrease of proliferation was recorded for all S. aureus. Authors highlighted that the production of chemokines was significantly diminished following treatment with the anti-inflammatory molecule. Chemokine levels in the supernatant derived from MG-63 cells infected with $S$. aureus and pre-treated with SPEP were slightly lower than in the supernatant derived from MG-63 cells infected with SPEP-untreated bacteria. This is a consequence of the reduced internalization of SPEP-pretreated bacteria: lower internalization leads to less stimulation and lower production of the pro-inflammatory chemokine MCP-1 (Selan et al 2017).

\section{Antimicrobial activity against intra-osteoblastic pathogens}

S. aureus can invade osteoblastic cells, which evade the immune response of the host and become a reservoir of bacteria, somewhat protected from the activity of many antimicrobial molecules. 
Valour et al. (2015-a) evaluated the efficacy of antimicrobial therapy in S. aureus BJI. They evaluated the intraosteoblastic activity of the main antimicrobial agents used for Staphylococcal BJI in an in vitro model of osteoblast infection. An infection assay with a MOI of 100:1 was employed, incubating all cells with three different concentrations for each antibiotic.

Inside the bones, vancomycin and daptomycin reach concentrations that cannot significantly prevent bacteria intracellular growth, while an intracellular bacteriostatic effect was observed using ceftaroline and teicoplanin. A significant intracellular bactericidal effect was observed for fosfomycin, linezolid, tigecycline, oxacillin, rifampin, ofloxacin and clindamycin. At minimum concentration, only rifampin, ofloxacin and fosfomycin were bactericidal. At maximum concentration, all aforementioned antibiotics were bactericidal, with the exception of vancomycin and daptomycin. Furthermore, at intracellular concentration, the number of SCVs significantly decreased in the osteoblasts treated with ofloxacin, rifampin and daptomycin. In addition, oxacillin, ceftaroline, linezolid, fosfomycine and tigecycline reduced the proportion of intracellular SCVs, but only at their maximum concentration.

Considering that intra-osteoblastic S. aureus constitutes a bacterial reservoir leading to chronicity and relapse, targeting intracellular bacteria might be a major therapeutic issue in the antimicrobial therapy for BJI (Rasigade et al.2013, Valour et al., 2015-b).

Vancomycin intracellular efficacy is lower than that of teicoplanin, probably due to its slow uptake and accumulation in the cell. Conversely, rifampin and fluoroquinolones have a fast intra-cellular uptake. Previously published studies showed that the intracellular activity of anti-staphylococcal drugs depends on the exposure time and extracellular concentration of the molecule tested, which emphasizes the importance of using therapeutic bone concentration. When using systemic therapeutic concentrations, only ofloxacin was able to limit the intracellular emergence of SCVs.

An association of levofloxacin and rifampin is the elective treatment for acute staphylococcal PJI managed with debridement, antibiotics and implant retention (DAIR) (Ariza et al. 2017, Osmon et al., 2013). This regime is bactericidal and highly active against biofilm-embedded staphylococci and has good bioavailability and bone diffusion (Muller-Serieys et al., 2009). 
Meléndez-Carmona et al (2019) evaluated the effects of rifampin and levofloxacin, alone and in combination, against the process of MSSA internalization in MG-63 cells using a MOI of 100:1. Both antibiotics showed a significant CFU decrease (a Log10 of CFU) compared to bacterial CFUs within untreated cells, whereas the association did not show higher activity compared to levofloxacin monotherapy. Rifampin, alone and in combination with levofloxacin, showed a significant increase in the percentage of SCVs and a significant reduction in the number of intracellular CFUs in comparison with untreated osteoblast cells (Meléndez-Carmona et al., 2019).

Dupieux et al. (2017) demonstrated that using S. aureus strains to infect osteoblast, daptomycin did not reduce MSSA number and was poorly active against MRSA. Instead oxacillin and ceftaroline revealed significant intracellular activity, although oxacillin is not usually active against MRSA. In this paper two different molecular combinations were proved, in particular: daptomycin/oxacillin was more active against intracellular MSSA and MRSA compared with daptomycin and oxacillin alone; and daptomycin/ceftaroline was less efficient than ceftaroline alone. It seems that in acid intracellular conditions oxacillin was able to enhance daptomycin activity versus S. aureus.

Abad et al. (2019) demonstrated that linezolid and tedizolid, in intracellular condition, were able to poorly reduce the inoculum of $S$. aureus and this reduction was strain-dependent, - not MIC dependent - but improved cell viability. These two oxazolidinones alone are not useful versus $S$. aureus strains associated with chronic forms of BJI due to their weak intracellular activity, but they are able to reduce infection-related cytotoxicity, suggesting a role in modulating intracellular expression of staphylococcal virulence factors.

\section{Conclusion}

We believe that the use of an osteoblastic stabilized line, such as MG-63, although different from primary osteoblasts in some respects, allows to standardize studies aiming to obtain further information to predict the capability of staphylococcal clones - often associated with recurrent and chronic infections - to invade, internalize and persist within the human cells, as well as to confirm the active role of osteoblasts in the host defenses against $S$. aureus infection. 
Author Contributions: Conceptualization, N.M., D.B., S.Str and S.S.; writing/original draft preparation, L.M.L. and A.C; writing/review and editing, S.Str., N.M., D.B. and S.S.; funding acquisition, D.B. and S.S. All authors have read and agreed to the published version of the manuscript.

Acknowledgments: We wish to thank Floriana Campanile for her support and suggestions.

Conflicts of Interest: The authors declare no conflict of interest.

Ethics statement: None required.

Funding: The authors received no financial support for the authorship, and/or publication of this article. 


\section{REFERENCES}

Abad, L.; Tafani, V.; Tasse, J.; Josse, J.; Chidiac, C.; Lustig, S.; Ferry, T.; Diot, A.; Laurent, F.; Valour F. Evaluation of the ability of linezolid and tedizolid to eradicate intraosteoblastic and biofilmembedded Staphylococcus aureus in the bone and joint infection setting. J Antimicrob Chemother. 2019 Mar 1;74(3):625-632. doi: 10.1093/jac/dky473.

Abe, Y.; Aida, Y.; Abe, T.; Hirofuji, T.; Anan, H.; Maeda, K. Development of mineralized nodules in fetal rat mandibular osteogenic precursor cells: Requirement for dexame-thasone but not for betaglycerophosphate. Calcif Tissue Int. 2000, 66:66-69.

Alekseeva, L.; Rault, L.; Almeida, S.; Legembre, P.; Edmond, V.; Azevedo, V.; Miyoshi, A.; Even, S.; Taieb, F.; Arlot-Bonnemains, Y.; Le Loir, Y.; Berkova, N. Staphylococcus aureus-induced G2/M phase transition delay in host epithelial cells increases bacterial infective efficiency. PLoS One 2013, 8, e63279.

Alto, N.M.; Orth, K. Subversion of cell signaling by pathogens. Cold Spring Harb Perspect Biol. 2012, 4, a006114.

Ahmed, S.; Meghji, S.; Williams, R.J.; Henderson, B.; Brock, J.H.; Nair, S.P. Staphylococcus aureus fibronectin binding proteins are essential for Internalization by osteoblasts but do not account for differences in intracellular levels of bacteria. Infect. Immun. 2001 69,28722877. doi:10.1128/IAI.69.5.2872-2877.2001.

Arciola, C.R.; Campoccia, D.; Baldassarri, L.; Pirini, V.; Huebner, J.; Montanaro, L. The role of Enterococcus faecalis in orthopedic peri-implant infections demonstrated by automated ribotyping and cluster analysis. Biomaterials 2007, 28:3987-3995. 
Arciola, C.R.; Campoccia, D.; Speziale, P.; Montanaro, L.; Costerton, J.W. Biofilm formation in Staphylococcus implant infections. A review of molecular mechanisms and implications for biofilmresistant materials. Biomaterials 2012, 33:5967-5982.

Ariza, J.; Cobo, J.; Baraia-Etxaburu, J.; Benito, N.; Bori, G.; Cabo, J.; Corona, P.; Esteban, J.; Horcajada, J.P.; Lora-Tamayo, J; et al. Executive summary of management of prosthetic joint infections. Clinical practice guidelines by the Spanish Society of Infectious Diseases and Clinical Microbiology (SEIMC). Enferm Infecc Microbiol Clin. 2017, 35:189-95.

Bhagat, S.; Agarwal, M.; Roy, V. Serratiopeptidase: a systematic review of the existing evidence. Int J Surg. 2013, 11(3):209-17. doi: 10.1016/j.ijsu.2013.01.010. Epub 2013 Feb 1.

Bhavsar, A.P.; Guttman, J.A.; Finlay, B.B. Manipulation of host-cell pathways by bacterial pathogens. Nature 2007, 449, 827-834.

Bellows, C.G.; Aubin, J.E.; Heersche, J.N.; Antosz, M.E. Mineralized bone nodules formed in vitro from enzymatically released rat calvaria cell populations. Calcif Tissue Int. 1986, 38:143-154.

Bergot, C.; Wu, Y.; Jolivet, E.; Zhou, L.Q.; Laredo, J.D.; Bousson, V. The degree and distribution of cortical bone mineralization in the human femoral shaft change with age and sex in a microradiographic study. Bone 2009, 45: 435-442.

Billiau, A.; Edy, V.G.; Heremans, H.; Van, D.J.; Desmyter, J.; Georgiades, J.A.; De, S.P. Human interferon: Mass production in a newly established cell line, MG-63. Antimicrob Agents Chemother. $1977,12: 11-15$.

Bost, K.L.; Bento, J.L.; Petty, C.C.; Schrum, L.W.; Hudson, M.C.; Marriott, I. Monocyte chemoattractant protein-1 expression by osteoblasts following infection with Staphylococcus aureus or Salmonella. J Interferon Cytokine Res. 2001; 21(5):297-304. doi: 10.1089/107999001300177484. 
Bongiorno, D.; Musso, N.; Lazzaro L.M.; Mongelli, G.; Stefani, S.; Campanile F. Detection of methicillin-resistant Staphylococcus aureus persistence in osteoblasts using imaging flow cytometry. MicrobiologyOpen. 2020 vol. 9,5, e1017. doi:10.1002/mbo3.1017.

Bonjour, J.P.; Theintz, G.; Buchs, B.; Slosman, D.; Rizzoli, R. Critical years and stages of puberty for spinal and femoral bone mass accumulation during adolescence. J Clin Endocrinol Metab. 1991, 73: 555-563.

Brady, R.A.; Leid, J.G.; Calhoun, J.H.; Costerton, J.W.; Shirtliff, M.E. Osteomyelitis and the role of biofilms in chronic infection. FEMS Immunol Med Microbiol. 2008, 52: 13-22.

Campoccia, D.; Testoni, F.; Ravaioli, S.; Cangini, I.; Maso, A.; Speziale, P.; Montanaro, L.; Visai, L.; Arciola, C.R. Orthopedic implant infections: Incompetence of Staphylococcus epidermidis, Staphylococcus lugdunensis, and Enterococcus faecalis to invade osteoblasts. J Biomed Mater Res A. 2016, 104(3):788-801. doi: 10.1002/jbm.a.35564.

Campoccia, D.; Montanaro, L.; Ravaioli, S.; Cangini, I.; Testoni, F.; Visai, L.; Arciola C.R. New Parameters to Quantitatively Express the Invasiveness of Bacterial Strains from Implant-Related Orthopaedic Infections into Osteoblast Cells, Materials. 2018, 3;11(4):550.

Cao, X.Y.; Yin, M.Z.; Zhang L.N.; Li, S.P.; Cao, Y. Establishment of a new model for culturing rabbit osteoblasts in vitro. Biomed Mater. 2006, 1:L16-L19.

Chumduri, C.; Gurumurthy, R.K.; Zietlow, R.; Meyer, T.F. Subversion of host genome integrity by bacterial pathogens. Nat Rev Mol Cell Biol. 2016, 17,659-673.

Claro, T.; Widaa, A.; O’Seaghdha, M.; Miajlovic, H.; Foster, T.J.; O’Brien, F.J.; Kerrigan S.V. Staphylococcus aureus protein A binds to osteoblasts and triggers signals that weaken bone in osteomyelitis. PLoS One 2011, 6:e18748. doi: 10.1371/journal.pone.0018748. 
Collignon, H.; Davicco, M.J.; Barlet, J.P. Isolation of cells from ovine fetal long bone and characterization of their osteoblastic activities during in vitro mineralization. Arch Physiol Biochem. 1997, 105: 158-166;

Cohen, T.S.; Boland, M.L.; Boland, B.B.; Takahashi, V.; Tovchigrechko, A.; Lee, Y.; Sellman, B.R. S. aureus evades macrophage killing through NLRP3-dependent effects on mitochondrial trafficking. Cell Reports 2018, 22, 2431-2441.

Costerton, J.W.; Stewart, P.S.; Greenberg, E.P. Bacterial biofilms: a common cause of persistent infections. Science 1999, 284: 1318-1322.

Czekanska, E.M.; Stoddart, M.J.; Richards, R.G.; Hayes, J.S. In search of an osteoblast cell model for in vitro research. EurCells Mater. 2012, 24: 1-17.

Czekanska, E.M.; Stoddart, M.J.; Ralphs, J.R.; Richards, R.G.; Hayes, J.S. A phenotypic comparison of osteoblast cell lines versus human primary osteoblasts for biomaterials testing. J Biomed Mater Res A 2014, 102(8): 2636-43.

Deplanche, M.; El-Aouar Filho, R.A.; Alekseeva, L.; Ladier, E.; Jardin, J.; Henry, G.; Azevedo, V.; Miyoshi, A.; Beraud, L.; Laurent, F.; et al. Phenol-soluble modulin $\alpha$ induces G2/M phase transition delay in eukaryotic HeLa cells. FASEB J. 2015, 29(5):1950-9. doi: 10.1096/fj.14-260513. Epub 2015 Feb 3.

Deplanche, M.; Mouhali, N.; Nguyen, M.T.; Cauty, C.; Ezan, F.; Diot, A.; Raulin, L.; Dutertre, S.; Langouet, S.; Legembre, P.; et al. Staphylococcus aureus induces DNA damage in host cell. 2019, Sci Rep. 22;9(1):7694.

Dinarello, C.A.; Simon, A.; van der Meer, J.W.M. Treating inflammation by blocking interleukin-1 in a broad spectrum of diseases. Nature Reviews. Drug Discovery 2012, 11, 633-652. 
Ducy, P.; Zhang, R.; Geoffroy, V.; Ridall, A.L.; Karsenty, G. Osf2/Cbfa1: A transcriptional activator of osteoblast differentiation. Cell. 1997, 89: 747-754.

Dupieux, C.; Trouillet-Assant, S.; Camus, C.; Abad, L.; Bes, M.; Benito, Y.; Chidiac, C.; Lustig, S.; Ferry, T.; Valour, F.; Laurent F. Intraosteoblastic activity of daptomycin in combination with oxacillin and ceftaroline against MSSA and MRSA. J Antimicrob Chemother. 2017 Dec 1;72(12):3353-3356. doi: $10.1093 / \mathrm{jac} / \mathrm{dkx} 314$.

Edwards, A.M.; Massey R.C. How does Staphylococcus aureus escape the bloodstream? Trends Microbiol. 2011, 19(4):184-90. doi: 10.1016/j.tim.2010.12.005. Epub 2011 Jan 10.

Ecarot-Charrier, B.; Glorieux, F.H.; van der Rest, M.; Pereira, G. Osteoblasts isolated from mouse calvaria initiate matrix mineralization in culture. J Cell Biol 1983, 96:639-643.

Ellington, J.K.; Reilly, S.S.; Ramp, W.K.; Smeltzer, M.S.; Kellam, J.F.; Hudson, M.C. Mechanisms of Staphylococcus aureus invasion of cultured osteoblasts. Microbial pathog. 1999 26: 317-323.

Ellington, J.K.; Harris, M.; Hudson, M.C.; Vishin, S.; Webb, L.X.; Sherertz, R. Intracellular Staphylococcus aureus and antibiotic resistance: Implications for treatment of staphylococcal osteomyelitis. J. Orthop. Res. 2006, 24, 87-93.

Fedarko, N.S.; Vetter, U.K.; Weinstein, S.; Robey, P.G. Age-related changes in hyaluronan, proteoglycan, collagen, and osteonectin synthesis by human bone cells. J Cell Physiol. 1992, 151: 215227.

Franceschi, R.T.; Romano, P.R.; Park, K.Y. Regulation of type I collagen synthesis by 1,25dihydroxyvitamin D3 in human osteosarcoma cells. J Biol Chem. 1988 263: 18938- 18945.

Hamza, T.; Li, B. Differential responses of osteoblasts and macrophages upon Staphylococcus aureus infection. BMC Microbiol. 2014, 14: 207. doi: 10.1186/s12866-014-0207-5. 
Harris, S.A.; Enger, R.J.; Riggs, B.L.; Spelsberg, T.C. Development and characterization of a conditionally immortalized human fetal osteoblastic cell line. J Bone Miner Res. 1995, 10:178 186.

Heilmann, C. Adhesion mechanisms of staphylococci. Advances in Experimental Medicine and Biology 2011, Vol.715,eds D. Linke and A. Goldman (Dordrecht: Springer),105-123;

Heng, Y.W.; Koh, C.G. Actin cytoskeleton dynamics and the cell division cycle. Int J Biochem Cell Biol. 2010, 42, 1622-1633. doi. org/10.1016/j.biocel.2010.04.007.

Heremans, H.; Billiau, A.; Cassiman, J.J.; Mulier, J.C.; de Somer, P. In vitro cultivation of human tumor tissues. II. Morphological and virological characterization of three cell lines. Oncology 1978, 35: 246252.

Hogan, A.; Heppert, V.G.; Suda, A.J. Osteomyelitis. Arch.Orthop. Trauma Surg. 2013, 133, 11831196. doi:10.1007/s00402-013-1785-7.

Hudson, M.C.; Ramp, W.K.; Nicholson,N.C.; Williams, A.S.; Nousiainen, M.T. Internalization of Staphylococcus aureus by cultured osteoblasts. Microb.Pathog. 1995, 19,409_ 419.doi:10.1006/mpat.1995.0075.

Jauregui, C.E.; Mansell, J.P.; Jepson, M.A.; Jenkinson, H.F. Differential interactions of Streptococcus gordonii and Staphylococcus aureus with cultured osteoblasts. Mol. Oral Microbiol. 2013, 28,250-266. doi:10.1111/omi.12022.

Jonsson, K.B.; Frost, A.; Nilsson, O.; Ljunghall, S.; Ljunggren, O. Three isolation techniques for primary culture of human osteoblast-like cells: a comparison. Acta Orthop Scand 1999, 70: 365-373. Johnson, K.S.; Ottemann, K.M. Colonization, localization, and inflammation: the roles of H. pylori chemotaxis in vivo. Curr Opin Microbiol 2017. 
Josse, J.; Velard, F.; Gangloff, S.C. Staphylococcus aureus vs Osteoblast: Relationship and Consequences in Osteomyelitis. Front Cell Infect Microbiol 2015, 5, 85. doi: 389 10.3389/fcimb.2015.00085.

Kasperk, C.; Wergedal, J.; Strong, D.; Farley, J.; Wangerin, K.; Gropp, H.; Ziegler, R.; Baylink, D.J. Human bone cell phenotypes differ depending on their skeletal site of origin. J Clin Endocrinol Metab. 1995, 80: 2511-2517.

Khalil, H.; Williams, R.J.; Stenbeck, G.; Henderson, B.; Meghji, S.; Nair, S.P. Invasion of bone cells by Staphylococcus epidermidis. MicrobesInfect. 2007, 9,460-465. doi:10.1016/j.micinf.2007.01.002.

Kim, P.H.; Leopold, S.S. Inbrief:Gustilo-Anderson classification. [corrected]. Clin.Orthop.Relat.Res. 2012, 470,3270 3274.doi:10.1007/s11999-012-2376-6.

Kirkham, G.; Cartmell, S. Genes and Proteins Involved in the Regulation of Osteogenesis. Topics in Tissue Engineering 2007, 3.

Lamkanfi, M.; Dixit, V.M. The Inflammasomes. PLoS Pathogens 2009, 5, e1000510.

Lamkanfi, M.; Dixit, V.M. Mechanisms and functions of inflammasomes. Cell 2014, 157, 1013-1022.

Leite, E.L.; Gautron, A.; Deplanche, M.; Nicolas, A.; Ossemond, J.; Nguyen, M.T.; do Carmo, F.L.R.; Gilot, D.; Azevedo, V.; Götz, F.; et al. Involvement of caspase-1 in inflammasomes activation and bacterial clearance in S.aureus-infected osteoblast-like MG-63 cells. Cell Microbiol. 2020, 22(8):e13204.

Lew, D.P.; Waldvogel, F.A. Osteomyelitis. Lancet 2004, 364,369-379.doi: 10.1016/S01406736(04)16727-5.

Maali, Y.; Martins-Simões, P.; Valour, F.; Bouvard, D.; Rasigade, J.P.; Bes, M.; Haenni, M.; Ferry, T.; Laurent, F.; Trouillet-Assant, S. Pathophysiological mechanisms of Staphylococcus non-aureus bone 
and joint infection: Interspecies homogeneity and specific behavior of S. pseudintermedius. Front. Microbiol. 2016, 7, 1063.

Mariathasan, S.; Newton, K.; Monack, D. M.; Vucic, D.; French, D.M.; Lee, W. P., Roose-Girma, M.; Erickson, S.; Dixit, V.M. Differential activation of the inflammasome by caspase-1 adaptors ASC and Ipaf. Nature, 2004, 430, 213-218.

Martinez, M.E.; Del Campo, M.T.; Medina, S.; Sanchez, M.; Sanchez-Cabezudo, M.J.; Esbrit, P.; Martinez, P.; Moreno, I.; Rodrigo, A.; Garces, M.V.; Munuera, L. Influence of skeletal site of origin and donor age on osteoblastic cell growth and differentiation. Calcif Tissue Int. 1999, 64: 280-286.

Meléndez-Carmona, M.Á.; Muñoz-Gallego, I.; Viedma, E.; Lora-Tamayo, J.; Chaves, F. Intraosteoblastic activity of levofloxacin and rifampin alone and in combination against clinical isolates of methicillin-susceptible Staphylococcus aureus causing prosthetic joint infection. Int J Antimicrob Agents. 2019, 54(3):356-360. doi: 10.1016/j.ijantimicag.2019.06.018. Epub 2019 Jun 26.

Miyamoto, K.; Ninomiya, K.; Sonoda, K.H.; Miyauchi, Y.; Hoshi, H.; Iwasaki, R.; Miyamoto, H.; Yoshida, S.; Sato, Y.; Morioka, H.; et al. MCP-1 expressed by osteoclasts stimulates osteoclastogenesis in an autocrine/paracrine manner. Biochem Biophys Res Commun. 2009, 5;383(3):373-7. doi: 10.1016/j.bbrc.2009.04.020. Epub 2009 Apr 11.

Montanaro, L.; Speziale, P.; Campoccia, D.; Ravaioli, S.; Cangini, I.; Pietrocola, G.; Giannini, S.; Arciola, C.R. Scenery of Staphylococcus implant infections in orthopedics. FutureMicrobiol. 2011, 6,1329-1349.doi:10.2217/fmb.11.117.

Muller-Serieys, C.; Saleh Mghir, A.; Massias, L.; Fantin B. Bactericidal activity of the combination of levofloxacin with rifampin in experimental prosthetic knee infection in rabbits due to methicillin- 
susceptible Staphylococcus aureus. Antimicrob Agents Chemother 2009, 53(5):2145-8. doi: 10.1128/AAC.01163-08.

Nair, S.P.; Bischoff, M.; Senn, M.M.; Berger Bächi, B. The sigma B regulon influences internalization of Staphylococcus aureus by osteoblasts. Infect. Immun. 2003, 71,4167-4170.doi:10.1128/IAI.71.7.41674170.2003.

Nguyen, M.T.; Deplanche, M.; Nega, M.; Le Loir, Y.; Peisl, L.; Götz, F.; Berkova, N. Staphylococcus aureus Lpl Lipoproteins Delay G2/M Phase Transition in HeLa Cells. Front Cell Infect Microbiol. 2016, 6, 201. doi: 10.3389/fcimb.2016.00201. eCollection 2016.

Otto, M. Basis of virulence in community-associated methicillinresistant Staphylococcus aureus. Annual Review of Microbiology 2010, 64, 143-162.

Osmon, D.R.; Berbari, E.F.; Berendt, A.R.; Lew, D.; Zimmerli, W.; Steckelberg, J.M.; Rao, N.; Hanssen, A.; Wilson, W.R. Diagnosis and management of prosthetic joint infection: clinical practice guidelines by the Infectious Diseases Society of America. Clin Infect Dis 2013, 56:e1-25.

Papa, R.; Artini, M.; Cellini, A.; Tilotta, M.; Galano, E.; Pucci, P.; Amoresano, A.; Selan, L. A new antiinfective strategy to reduce the spreading of antibiotic resistance by the action on adhesion-mediated virulence factors in Staphylococcus aureus. Microb Pathog. 2013, 63:44-53. doi: 10.1016/j.micpath.2013.05.003. Epub 2013 Jun 26.

Pautke, C.; Schieker, M.; Tischer, T.; Kolk, A.; Neth, P.; Mutschler, W.; Milz, S. Characterization of osteosarcoma cell lines MG- 63, Saos-2 and U-2 OS in comparison to human osteoblasts. Anticancer Res. 2004, 24(6): 3743-8.

Ponten J.; Saksela, E. Two established in vitro cell lines from human mesenchymal tumors. Int J 
Queck, S.Y.; Jameson-Lee, M.; Villaruz, A.E.; Bach, T.H.L.; Khan, B.A.; Sturdevant, D.E.; Otto, M. RNAIII-independent target gene control by the agr quorum-sensing system: Insight into the evolution of virulence regulation in Staphylococcus aureus. Molecular Cell. 2008, 32, 150-158.

Rasigade, J.P.; Trouillet-Assant, S.; Ferry, T.; Diep, B.A.; Sapin, A.; Lhoste, Y.; Ranfaing, J.; Badiou, C.; Benito, Y.; Bes, M.; et al. PSMs of hypervirulent Staphylococcus aureus act as intracellular toxins that kill infected osteoblasts PLoS One 2013, 8:e63176.

Reinhardt, H.C.; Yaffe, M.B. Kinases that control the cell cycle in response to DNA damage: Chk1, Chk2, and MK2. CurrOpinCellBiol. 2009, 21, 245-255, https://doi.org/10.1016/j.ceb.2009.01.018.

Ryoo. H.M.; Hoffmann, H.M.; Beumer, T.; Frenkel, B.; Towler, D.A.; Stein, G.S.; Stein, J.L.; van Wijnen, A.J.; Lian, J.B. Stage-specific expression of Dlx-5 during osteoblast differentiation: Involvement in regulation of osteocalcin gene expression. Mol Endocrinol. 1997, 11: 1681-1694.

Rodan, S.B.; Imai, Y.; Thiede, M.A.; Wesolowski, G.; Thompson, D.; Bar-Shavit, Z.; Shull, S.; Mann, K.; Rodan, G.A. Characterization of a human osteosarcoma cell line (Saos-2) with osteoblastic properties. Cancer Res. 1987, 47:4961-4966.

Rupes, I.; Webb, B.A.; Mak, A.; Young, P.G. G2/M arrest caused by actin disruption is a manifestation of the cell size checkpoint in fission yeast. Mol Biol Cell. 2001, 12(12):3892-903. doi: 10.1091/mbc.12.12.3892.

Schinke, T.; Karsenty, G. Transcriptional control of osteoblast differentiation and function. Principles of Bone Biology. London: Academic Press; 2002, 83-92.

Schroder, K.; Tschopp, J. The inflammasomes. Cell 2010, 140, 821-832. 
Selan, L.; Papa, R.; Tilotta, M.; Vrenna, G.; Carpentieri, A.; Amoresano, A.; Pucci, P.; Artini, M. Serratiopeptidase: a well-known metalloprotease with a new non-proteolytic activity against $S$. aureus biofilm. BMC Microbiol. 2015, 9;15:207. doi: 10.1186/s12866-015-0548-8.

Selan, L.; Papa, R.; Ermocida, A.; Cellini, A.; Ettorre, E.; Vrenna, G.; Campoccia, D.; Montanaro, L.; Arciola, C.R.; Artini, M. Serratiopeptidase reduces the invasion of osteoblasts by Staphylococcus aureus. Int J Immunopathol Pharmacol. 2017, 30(4):423-428. doi: 10.1177/0394632017745762. Epub 2017 Dec 7.

Smith, J.L.; Bayles, D.O. The contribution of cytolethal distending toxin to bacterial pathogenesis. Crit Rev Microbiol. 2006, 32, 227-248,https://doi.org/10.1080/10408410601023557.

Sokolovska, A.; Becker, C.E.; Ip, W.K.E.; Rathinam, V.A.K.; Brudner, M.; Paquette, N.; Stuart, LM. Activation of caspase-1 by the NLRP3 inflammasome regulates the NADPH oxidase NOX2 to control phagosome function. Nature Immunology 2013, 14, 543-553.

Spellberg, B.; Lipsky, B.A. Systemic antibiotic therapy for chronic osteomyelitis in adults. Clin. Infect. Dis. 2012, 54,393-407. doi:10.1093/cid/cir842.

Stewart, P.S.; Costerton, J.W. Antibiotic resistance of bacteria in biofilms. Lancet 2001, 358:135-138.

Strowig, T.; Henao-Mejia, J.; Elinav, E.; Flavell, R. Inflammasomes in health and disease. Nature 2012, $481,278-286$.

Syed, A.K.; Reed, T.J.; Clark, K.L.; Boles, B.R.; Kahlenberg, J.M. Staphylococcus aureus phenol-soluble modulins stimulate the release of proinflammatory cytokines from keratinocytes and are required for induction of skin inflammation. Infect Immun. 2015, 83:3428-3437. doi:10.1128/IAI.00401-15. 
Testoni, F.; Montanaro, L.; Poggi, A.; Visai, L.; Campoccia, D.; Arciola, C.R. Internalization by osteoblasts of two Staphylococcus aureus clinical Isolates differing in their adhesin gene pattern. Int. J. Artif. Organs 2011, 34,789-798. doi:10.5301/ijao.5000058.

Trouillet-Assant, S.; Lelièvre, L.; Martins-Simões, P.; Gonzaga, L.; Tasse, J.; Valour, F.; Rasigade, J.P.; Vandenesch, F.; Muniz Guedes, R.L.; Ribeiro de Vasconcelos, A.T.; et al. Adaptive processes of Staphylococcus aureus isolates during the progression from acute to chronic bone and joint infections in patients. Cell Microbiol. 2016, 18, 1405-1414.

Tucker, K.A.; Reilly, S.S.; Leslie, C.S.; Hudson, M.C. Intracellular Staphylococcus aureus induces apoptosis in mouse osteoblasts. FEMS Microbiol. Lett. 2000, 186,151-56.doi:10.1111/j.15746968.2000.tb09096.x.

Turner, M.D.; Nedjai, B.; Hurst, T.; Pennington, D.J. Cytokines and chemokines: at the crossroads of cell signalling and inflammatory disease. Bio-chim. Biophys. Acta 2014, 1843,2563-2582. doi:10.1016/j.bbamcr.2014.05.014

Valour, F.; Trouillet-Assant, S.; Rasigade, J.P.; Lustig, S.; Chanard, E.; Meugnier, H.; Tigaud S.; Vandenesch, F.; Etienne, J.; Ferry, T.; Laurent, F.; Lyon, B.J.I. Study Group. Staphylococcus epidermidis in orthopedic device infections: The role of bacterial internalization in human osteoblasts and biofilm formation. PLoS One 2013, 8: e67240

Valour, F.; Trouillet-Assant, S.; Riffard, N.; Tasse, J.; Flammier, S.; Rasigade, J.P.; Chidiac, C.; Vandenesch, F.; Ferry, T.; Laurent F. Antimicrobial activity against intraosteoblastic Staphylococcus aureus, Antimicrob Agents Chemother. 2015-a, 59(4):2029-36. Epub 2015 Jan 20. doi:10.1128/AAC.04359-14t 
Valour, F.; Rasigade, J.P.; Trouillet-Assant, S.; Gagnaire, J.; Bouaziz, A.; Karsenty, J.; Lacour, C.; Bes, M.; Lustig, S.; Bénet T.; et al. Delta-toxin production deficiency in Staphylococcus aureus: a diagnostic marker of bone and joint infection chronicity linked with osteoblast invasion and biofilm formation, Clin Microbiol Infect. 2015-b, (6):568.e1-11.. Epub 2015 Feb 10.

van Loon, B.; Markkanen, E.; Hübscher, U. Oxygen as a friend and enemy: How to combat the mutational potential of 8-oxo-guanine. DNA Repair (Amst) 2010, 9(6):604-16. doi: 10.1016/j.dnarep.2010.03.004.

Voegele, T.J.; Voegele-Kadletz, M.; Esposito, V.; Macfelda, K.; Oberndorfer, U.; Vecsei, V.; Schabus, R. The effect of different isolation techniques on human osteoblast-like cell growth. Anticancer Res. 2000, 20: 3575-3581.

Wang, D.; Christensen, K.; Chawla, K.; Xiao, G.; Krebsbach, P.H.; Franceschi, R.T. Isolation and characterization of MC3T3-E1 preosteoblast; subclones with distinct in vitro and in vivo differentiation/mineralization potential. J Bone Miner Res. 1999, 14:893-903.

Wenstrup, R.J.; Witte, D.P.; Florer, J.B. Abnormal differentiation in MC3T3-E1 preosteoblasts expressing a dominant-negative type I collagen mutation. Connect Tissue Res 1996, 35:249-257.

Widaa, A.; Claro,T.; Foster, T.J.; O’Brien, F.J.; Kerrigan, S.W. Staphylococcus aureus protein a plays a critical role in mediating bone destruction and bone loss in osteomyelitis. PLoS One 2012, 7:e40586.doi: 10.1371/journal.pone.0040586.

Zhu, X.; Zhang, K.; Lu, K.; Shi, T.; Shen, S.; Chen, X.; Dong, J.; Gong, W.; Bao, Z.; Shi, Y; et al. Inhibition of pyroptosis attenuates-induced bone injury in traumatic osteomyelitis. Annals of Translational Medicine 2019, 7, 170. 